\title{
Comparative Electron Energy-Loss Near-Edge Fine Structure Investigations Of
}

\section{Titanium Oxides}

\author{
C. Mitterbauer ${ }^{+}$, G. Kothleitner ${ }^{+}$and F. Hofer ${ }^{+}$, \\ ${ }^{+}$Research Institute for Electron Microscopy, Graz University of Technology, Steyrergasse 17, \\ A-8010 Graz, Austria
}

Near-edge fine structures in electron energy-loss spectroscopy (ELNES) contain information about the local bonding and environment of atoms in solids. These fine-structure arise because the final states of the excitation process may be appreciably modified by chemical bonding [1]. A pragmatic approach to ELNES is collecting "fingerprints" from elements in similar compounds and to identify common features in order to derive bonding information [2].

For this study we have collected ELNES-data from different titanium oxides with varying stoichiometry. Special attention was paid to the low loss region, as well as to the $\mathrm{Ti}_{2,3}$ and O K edges of the compounds $\mathrm{TiO}_{2}$ (rutile, brookite and anatase), $\mathrm{Ti}_{2} \mathrm{O}_{3}, \mathrm{TiO}_{\mathrm{x}}$ (with $\mathrm{x}$ varying from 0.8 to 1.2) and $\mathrm{Ti}_{2} \mathrm{O}$. The spectra have been acquired on a $200 \mathrm{kV}$ Philips CM20 + GIF, operated with an undersaturated $\mathrm{LaB}_{6}$ cathode. The energy resolution in these spectra was found to be $\sim 0.7 \mathrm{eV}$ (FWHM at the zero loss peak) during 1s exposure time and never exceed $0.9 \mathrm{eV}$ for an acquisition time of 30 seconds.

$\mathrm{TiO}_{2}$ forms three distinct polymorphs: rutile and anatase with a tetragonal structure and orthorhombic brookite. The crystal structure of $\mathrm{Ti}_{2} \mathrm{O}_{3}$ on the other hand is trigonal. $\mathrm{TiO}_{\mathrm{x}}$ is cubic and exists within a stoichiometric range from $\mathrm{TiO}_{0.58}$ to $\mathrm{TiO}_{1.33}$. In all these compounds the titanium atoms are surrounded by six oxygen atoms. These coordinating oxygen octahedra are slightly distorted and the distortion decreases from $\mathrm{TiO}_{2}(\leq 0.06 \AA$ for the $\mathrm{Ti}-\mathrm{O}$ distances $)$ to $\mathrm{TiO}_{\mathrm{x}}[3]$. Trigonal $\mathrm{Ti}_{2} \mathrm{O}$ exhibits ordered arrangements of the oxygen atoms in the octahedral voids of hcp titanium and shows no octahedral coordination of the oxygen around the titanium atoms.

FIG. 1. shows the low loss spectra of the analyzed compounds. One can see increased separation of the second feature (10-25 eV; originating from interband transitions) going from $\mathrm{Ti}_{2} \mathrm{O}$ to the $\mathrm{TiO}_{2}$ modifications which is accompanied by a change from metallic $\left(\mathrm{Ti}_{2} \mathrm{O}\right.$ and $\left.\mathrm{TiO}\right)$ to semiconducting $\left(\mathrm{Ti}_{2} \mathrm{O}_{3}\right)$ to insulating $\left(\mathrm{TiO}_{2}\right)$ behavior. There is also a shift of the $\mathrm{M}_{2,3}$ edge (48 eV) to lower energyloss with decreasing titanium valence state.

The left part of FIG. 2 represents the Ti $\mathrm{L}_{2,3}$ edges of the different titanium oxides. The octahedral ligand-field causes the five degenerated $d$ states in the conduction band to split into the twofold $e_{g}$ states, and the threefold $t_{2 \mathrm{~g}}$. The presence of distortions from octahedral symmetry causes further splitting (e.g. the $\mathrm{L}_{3}-\mathrm{e}_{\mathrm{g}}$ feature of the $\mathrm{TiO}_{2}$-modifications). Going from top to bottom the ligand-field splitting decreases and both $\mathrm{L}$ edges shift to lower energies.

Like the Ti $\mathrm{L}_{2,3}$ edge the $\mathrm{O} \mathrm{K}$ edge (right side in FIG. 2) is effected by the octahedral ligand-field as well. The splitting into $t_{2 \mathrm{~g}}$ - and $\mathrm{e}_{\mathrm{g}}$-features is reduced with decreasing oxygen content and the $\mathrm{O} \mathrm{K}$ edge shifts to higher energy loss [4].

The aim of this work was to systematically study the influence of different oxidation states as well as the influence of the environment of particular crystallographic sites on the ELNES for the above mentioned ionization edges [5]. 


\section{References}

[1] R Brydson, EMSA Bulletin 21 (1991) 57

[2] F. Hofer and P. Golob, Ultramicroscopy 21 (1987) 379

[3] R.W.G. Wyckoff, Crystal Structures vol 1, Wiley-Interscience, New York, 1960

[4] M. Yoshiya et al., J. Phys.: Condens. Matter 11 (1999) 3217

[5] We gratefully acknowledge financial support by the Austrian Science Foundation (FWF) within the Special Research Program 'Electroactive Materials' and E. Krautz, Institute of Solid State Physics, Graz University of Technology, for sample preparation.

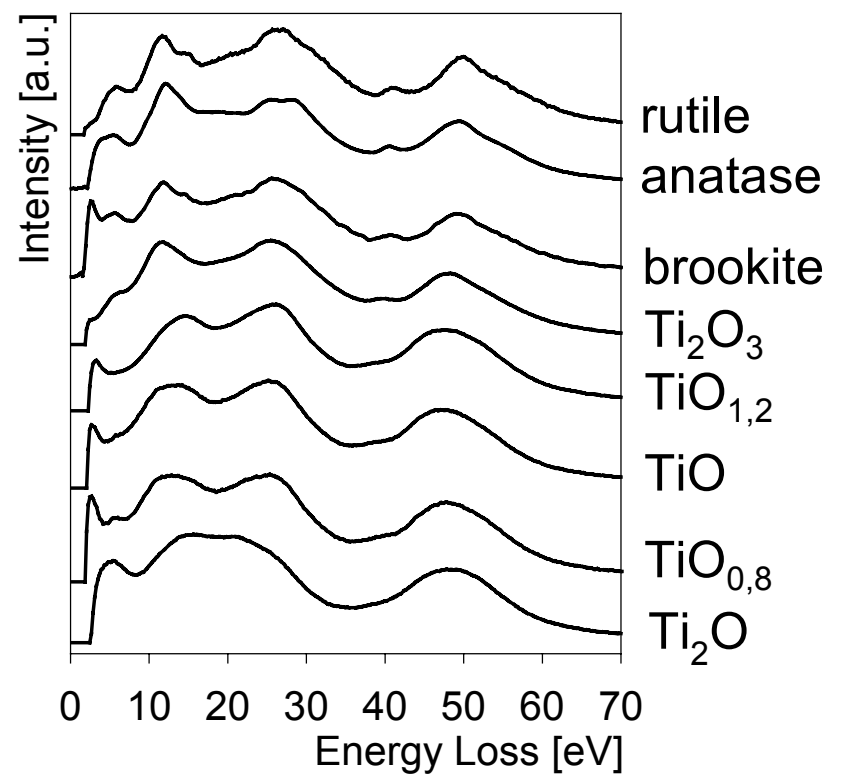

FIG. 1 Low loss spectra of different titanium oxides (all spectra are Fourier log deconvoluted)
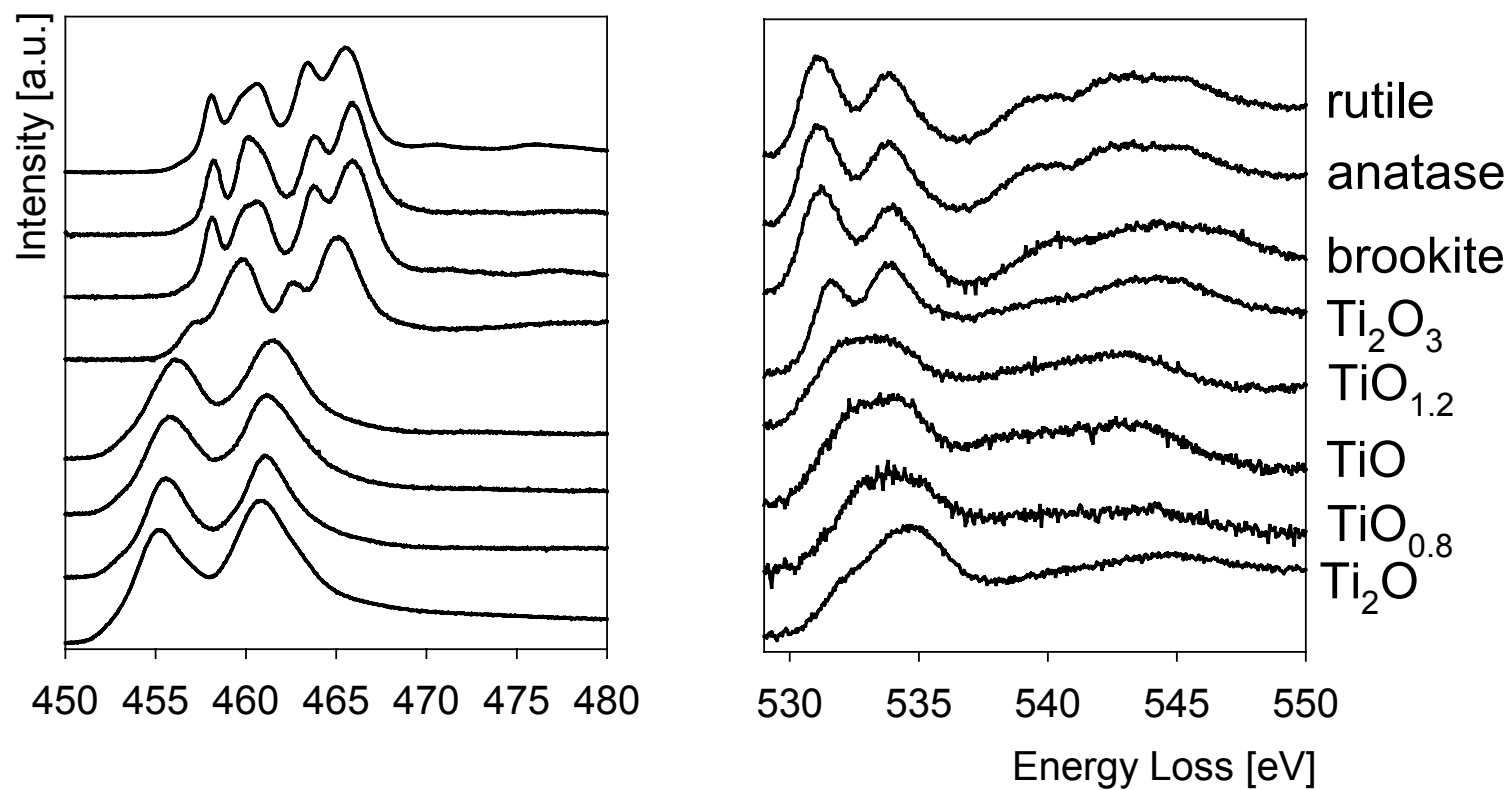

FIG. 2. Ti $\mathrm{L}_{2,3}$ and $\mathrm{O} \mathrm{K}$ edge spectra of different titanium oxides (all spectra are Fourier ratio deconvoluted) 